\title{
Amyloidosis of the orbit and adnexia
}

\author{
Sadia Sultana ${ }^{1, *}$, Nazmul Haque Robi ${ }^{2}$, Riffat Rashid ${ }^{3}$, Syeed Mehbub UI Kadir ${ }^{4}$ \\ ${ }^{1,2}$ Associate Professor, ${ }^{3}$ Assistant Professor, Dept. of Oculoplasty, Ispahani Islamia Eye Institute and Hospital Dhaka, \\ Bangladesh, ${ }^{4}$ Consultant, Sheikh Fazilatunnesa Mujib Eye Hospital \& Training Institute, Bangladesh
}

*Corresponding Author:

Email: sadiasultanadr@yahoo.com

\begin{abstract}
Introduction: Primary localized periocular and orbital amyloidosis is a very rare condition. And due to lack of suspicion diagnosis of it is often delayed. We are describing five cases of primary localized orbital and adnexal amyloidosis including the demographic data, clinical features, histopathological features and treatment outcome.

Materials and Methods: This was a retrospective study that reviewed the clinical records of five patients with adnexal and orbital amyloidosis between January 2012 and December 2016. The mean follow up time was 12 months.

Results: The series included five patients (four female and one male). The mean age was 43.6 (range: $35-55$ years). Three cases had bilateral lesion and two had unilateral lesion. The average duration from the time of onset to presentation was 10.2 years (range: 7 to 15 years). The most common symptom was a mass lesion (100\%), followed by irritation (40\%) and ptosis (40\%) and restricted ocular motility (20\%). Four cases had periocular and one case had orbital involvement. The main treatment option was surgical excision.

Conclusion: Periocular and orbital amyloidosis can present in a variety of ways. A mass lesion is the most common symptom. Surgical excision resulted in good outcome. Clinical evaluation and investigation should be done in all cases to exclude systemic involvement.
\end{abstract}

Keywords: Amyloid, Orbital mass.

\section{Introduction}

Amyloidosis has got a heterogenous presentation and it is characterized by extracellular amyloid deposits in different organs. ${ }^{1}$ Congo red staining is used as the gold standard for diagnosis of amyloidosis, which reveals apple-green birefringence. ${ }^{2}$ Depending on the etiology, clinical findings or familial predisposition, amyloidosis can be classified in many ways. ${ }^{3,5}$ Localized amyloidosis involves only one organ, and systemic amyloidosis has got widespread involvement affecting multiple organs. When there is no underlying clinical condition responsible, it is named as primary amyloidosis or idiopathic amyloidosis. Secondary amyloidosis often results from chronic inflammatory conditions such as rheumatoid arthritis, chronic infections etc. ${ }^{5}$ In periocular and orbital amyloidosis, lacrimal gland, eyelid, conjunctiva, and ocular adnexa are commonly involved. And in most of the patients, these are primary localized diseases. However, investigation should be done in all patients to rule out systemic involvement. Amyloidosis progressively destroys the involved tissues. ${ }^{2}$ Progressive amyloid depositions disrupt tissue structure and impair its function. Clinical presentation of amyloidosis can vary immensely. When major organs like kidney or heart is involved, the consequences can be fatal. ${ }^{6,7}$ However, localized amyloidosis is usually benign and has got no effect on survival. As periocular and orbital amyloidosis is rare, definitive diagnosis is often delayed due to lack of suspicion. It allows disease progression. ${ }^{8,10}$ There are a number of case reports, and a single large case series that describes the clinical features and prognosis of periocular amyloidosis. ${ }^{11,17}$ We report five cases of amyloidosis involving several locations, their clinical and histological features, and treatment outcomes.

\section{Materials and Methods}

This is a retrospective study that collected data from clinical records. Five patients were diagnosed with periocular and orbital amyloidosis between March 2012 and December 2016. The diagnosis of periocular and orbital amyloidosis was confirmed by tissue histopathology. We reviewed the clinical records of these patients: demographic data, the duration of clinical presentation, location of disease, the histopathologic result and treatment modalities, and outcome. The study was approved by the human ethics committee of Ispahani Islamia Eye Institute \& Hospital, Dhaka, Bangladesh.

\section{Results}

Our study had five patients (4 female and 1 male). The mean age was 43.6 (range 35-55 years). There were three cases of bilateral and two cases of unilateral lesion. The mean duration of initial symptom was 10.2 years (range: $7-15$ years). The medical history of all patients was non contributory. There was no history of trauma. None of them had any inflammatory diseases which can lead to amyloidosis. The visual acuity of four patients was 20/20. In one patient the visual acuity was counting finger from corneal vascularization. The patient data and details are recorded in Table 1. 
Table 1: Characteristics of patients with periocular and orbital amyloidosis

\begin{tabular}{|l|l|l|c|c|c|c|c|}
\hline $\begin{array}{c}\text { Case } \\
\text { No. }\end{array}$ & Age/Sex & Eye & $\begin{array}{c}\text { symptoms, signs \& } \\
\text { duration }\end{array}$ & Sites & Treatment & Outcome & Follow up \\
\hline 1. & $35 / \mathrm{F}$ & Both & $\begin{array}{c}\text { Mass, irritation, 07 } \\
\text { years }\end{array}$ & Bulbar conjuctiva & Surgical excision & Stable & 09 months \\
\hline 2. & $55 / \mathrm{F}$ & Both & $\begin{array}{c}\text { Mass, irritation, 09 } \\
\text { years }\end{array}$ & Bulbar conjuctiva & Surgical excision & Stable & 11 months \\
\hline 3. & $47 / \mathrm{M}$ & Right & $\begin{array}{c}\text { Mass, } \\
10 \text { years }\end{array}$ & Rt. Lower lid & Surgical debulking & Stable & 10 months \\
\hline 4. & $40 / \mathrm{F}$ & Both & $\begin{array}{c}\text { Mass, ptosis, } \\
15 \text { years }\end{array}$ & ant. Orbit\& lid & Surgical debulking & Stable & 12 months \\
\hline 5. & $42 / \mathrm{F}$ & Left & $\begin{array}{c}\text { Mass, ptosis, } \\
10 \text { years }\end{array}$ & left upper lid & Surgical debulking & Stable & 18 months \\
\hline
\end{tabular}

The most common presentation was a mass lesion $(100 \%)$ in the eyelid, conjunctiva and orbit. Other presentations were ptosis (40\%) and irritation (40\%). Lid involvement was seen in 3 patients. The ptosis was mainly mechanical and resolved after excision of the mass. All patients had conjunctival cicatrization.
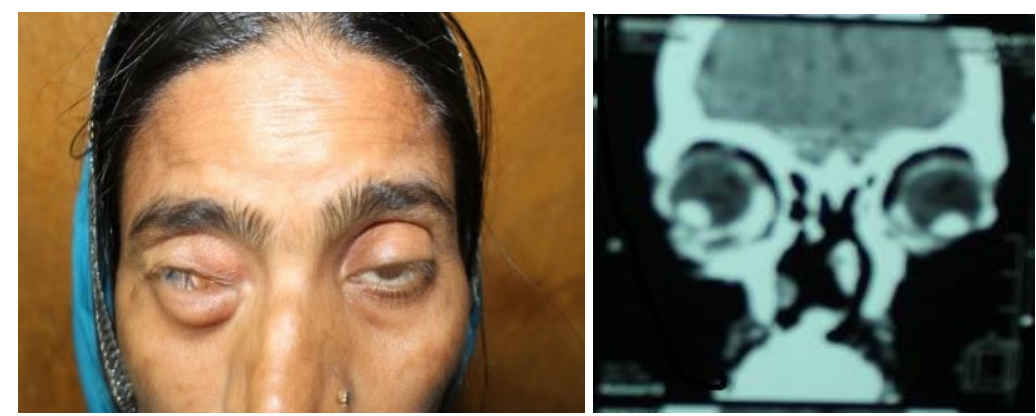

Fig. 1: Amyloidosis involving bilateral eye lids and right orbit (Anterior orbital mass and calcification in CT scan)
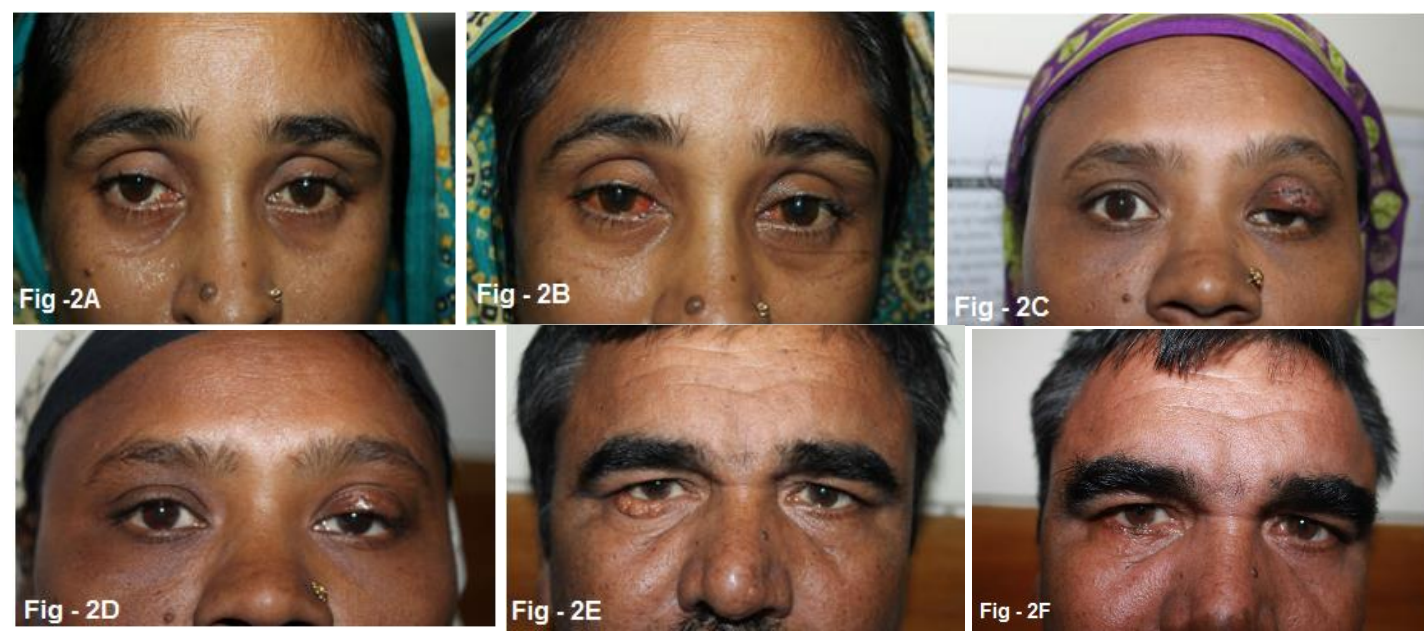

Fig. 2: Amyloidosis involving conjunctiva; (Fig. 2A: preoperative, Fig. 2B: postoperative); left upper lid (Fig. 2C: Preoperative; Fig. 2D: Postoperative) right lower lid; (Fig. 2E: Preoperative; Fig. 2F: Postoperative).

The anterior orbit and the lid were involved in one case. CT scan of orbit showed anterior orbital mass with calcification. No bony erosion was noted.

Systemic investigations like CBC, differential counts, ESR, Echo, USG of whole abdomen were done in all cases. But no evidence of systemic amyloidosis was found in any of the patients.
Two cases $(40 \%)$ were diagnosed by incisional biopsy. The histopathologies of all patients were reviewed. All cases were confirmed the diagnosis of amyloidosis by Congo red stain with apple- green birefringence by polarized light. 


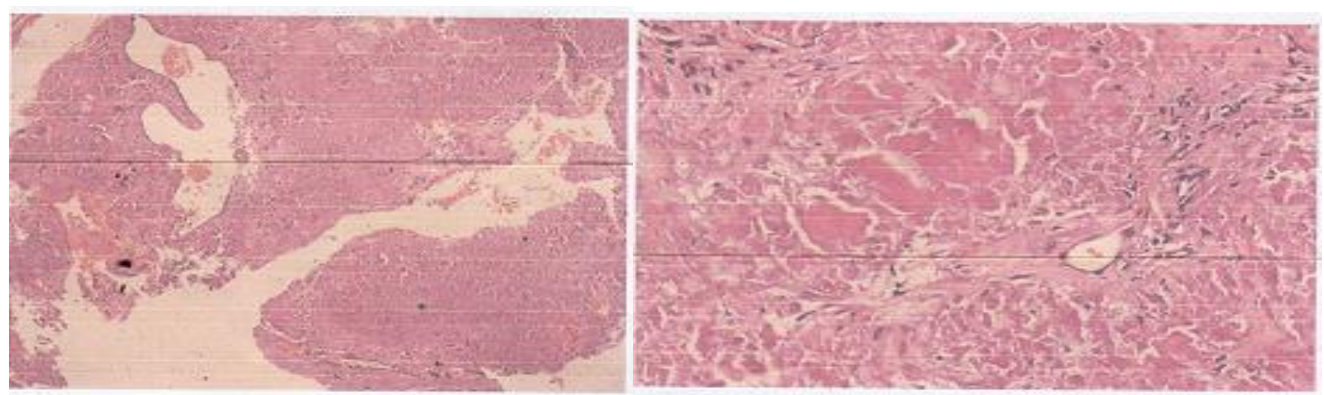

Fig 3: Histopathology of eye lid lesion showing amyloidosis (Congo red stain)

All the five cases underwent surgical debulking. All our patients were stable after surgery and recurrence was not found during follow up period. The mean follow up time was twelve months (range: 9-18 months).

\section{Discussion}

In our study, we present a case series with periocular and orbital amyloidosis, which is a very rare disease. We collected the data of patients who were treated over a period of five years.

The mean age of patients at presentation in this case series was 43.6 (range 35-55 years). But in other case series the age at presentation was wide and the mean age of presentation was 57 years (range 2785). ${ }^{11,18}$

Duration of symptoms varies in different studies. In one study of 24 patients with periocular and orbital amyloidosis, the mean duration of symptoms was 37 months. ${ }^{11}$ Orapan et al. found that mean duration of symptoms was 31 months in his case series of 6 patients. ${ }^{18}$ In our study, the mean duration of symptom was 10.2 years (range 7-15) which was quite variable. This long duration of symptoms of our study was comparable to the study of Al Hussain et al. which was 12 years. As the amyloid deposition occurs slowly, it is likely that patients seek attention at a more advanced stage. ${ }^{19}$

Four of our five patients were female. Al Hussain et al. also found that most patients in their series were female. ${ }^{19}$ But there is no large case series to conclude this gender predilection.

In our study, 3 patients $(60 \%)$ had bilateral involvement and two patients $(40 \%)$ had unilateral involvement. These figures are very comparable to the literature for conjunctival amyloidosis. Al- Nuaimi et al. found that $60 \%$ of the patients had unilateral involvement compared to $40 \%$ with bilateral involvement. $^{20}$

Mass lesion is the most common sign in previous studies of periocular and orbital amyloidosis. ${ }^{11,21} \mathrm{We}$ also found similar results where most common presenting complaint was a mass lesion (100\%) followed by ptosis (40\%) and ocular irritation (40\%).

Periocular and orbital amyloidosis may rarely be associated with systemic involvement like cardiac, cerebral, or renal amyloidosis. In our study, all five patients were worked up for systemic amyloidosis, and their results were negative.

Conjunctival amyloidosis leads to deposition of amyloid in the vessel wall and causes increased fragility of blood vessels. This often presents as recurrent subconjunctival haemorrhage. In the case series of Demirci et al. which was comprised of six patients of conjunctival amyloidosis, subconjunctival haemorrhage was present in $67 \%$ of the patients. ${ }^{21} \mathrm{We}$ had two cases of conjunctival amyloidosis but none of them were presented with subconjunctival haemorrhage. Recurrent subconjunctival haemorrhage was found in $12.5 \%$ of patients in another case series. ${ }^{11}$

Conjunctival amyloidosis is the commonest of the orbital amyloidosis. In one study $80 \%$ of their patients with orbital amyloidosis had conjunctival amyloidosis. $^{21}$ In our study, two cases $(40 \%)$ had conjunctival amyloidosis.

Fornices are the main site of involvement in conjunctival amyloidosis. ${ }^{11,22}$ It is postulated that the conjunctival amyloidosis usually begins in the fornices and spreads to the palpebral and bulbar part. ${ }^{23}$ This was not seen in our series of patients as the bulbar conjunctiva was the only involved site.

Conjunctival amyloidosis has also been reported to be associated with primary systemic amyloidosis, but only in 6\% cases. Orbital amyloidosis is mainly a localized disease. ${ }^{4,19,22,24,25} \mathrm{We}$ had two cases of conjunctival amyloidosis that did not have any systemic amyloidosis.

Ptosis is a common presenting feature in orbital amyloidosis. ${ }^{11,26-29}$ The mechanism of ptosis secondary to amyloidosis is felt to be mechanical or also due to infiltration of levator. In our study two (40\%) of the five patients had eyelid involvement with ptosis. Others have reported ptosis as a presenting sign in $50 \%$ of periorbital amyloidosis. ${ }^{11}$

Eyelid amyloidosis can be localized to eye and adnexa or part of the systemic amyloidosis. It is more frequently reported as an extension of conjunctival amyloidosis. ${ }^{27}$ In our two cases of eyelid amyloidosis, amyloid was primarily localized in the eyelid only. When amyloidosis is localized to eyelid, it results in ptosis. It can be managed by surgical excision of the mass, but sometimes require ptosis surgery. ${ }^{18}$ In our 
study we found the similar results because none of our patients with ptosis had underwent ptosis surgery.

Amyloid in the orbit is rare. It usually occurs in isolation, not as part of a systemic disease. Three most common presenting symptoms of orbital amyloidosis are - ptosis, proptosis and global displacement. ${ }^{30}$ Our single case of orbital amyloidosis also presented with ptosis and globe displacement.

The management of orbital amyloidosis is difficult, as the total excision is usually impossible. ${ }^{26}$ In our case also only debulking was done with preservation of vital structures.

Surgical intervention has been the primary treatment of choice to debulk the amyloidosis. Surgery can be challenging in some cases. Due to deposition of amyloid the tissues are abnormal and recurrence is an well documented phenomenon. ${ }^{22,27}$ Recurrence of orbital disease is considerably higher than that of conjunctival involvement alone $(29 \%$ and $15 \%$ respectively). ${ }^{11}$ All of our patients have remained stable with no recurrence or progression during follow up period of 12 months.

Conservative management in the treatment of orbital amyloidosis and in particular conjunctival amyloidosis should not be underestimated. When the patient is comfortable with the mass and there is no progression of amyloidosis, it is acceptable to observe the patient without doing surgery. ${ }^{21}$

\section{Conclusion}

Periocular and orbital amyloidosis is an extremely uncommon disease and it can present in a variety of ways. It often poses a diagnostic challenge. High degree of suspicion and histopathological investigation can detect the condition early. A work up for systemic involvement is mandatory in all cases, as it can change the survival of the patient. Most of the time periocular and orbital amyloidosis occur as a primary localized disease and can be managed by surgical debulking.

\section{Conflict of Interest: None}

\section{References}

1. Rootman J. Degenerations and depositions. In: Rootman J, editor. Diseases of the Orbit: A Multidisciplinary Approach, 2nd ed. Philadelphia, PA: Lippincott Williams \& Wilkins; 2003:555-564.

2. Picken MM. Amyloidosis-Where Are we now and where are we heading? Arch Pathol Lab Med 2010;134(4):545-551.

3. Holmström GE, Nyman KG. Primary orbital amyloidosis localised to an extraocular muscle. Br J Ophthalmol 1987;71(1):32-33.

4. Taban M, Piva A, See RF, Sadun AA, Quiros PA. Review: Orbital Amyloidosis. Ophthal Plast Reconstruct Surg 2004;20(2):162-165.

5. Khaira M, Mutamba A, Meligonis G, Rose GE, Plowman PN, O'Donnell H. The use of radiotherapy for the treatment of localized orbital amyloidosis. Orbit 2008;27(6):432-437.
6. Pepys MB. Amyloidosis. Ann Rev Med 2006;57(1):223241.

7. Buxbaum JN. The systemic amyloidoses. Curr Opin Rheumatol 2004;16(1):67-75.

8. Lee HJ, Chang SE, Lee MW, Choi JH, Moon KC. Systemic amyloidosis associated with multiple myeloma presenting as periorbital purpura. $J$ Dermatol 2008;35(6):371-372.

9. Goshe JM, Schoenfield L, Emch T, Singh AD. Myelomaassociated orbital amyloidosis. Orbit. 2010;29(5):274277.

10. Brown G, Shapeero LG, Weiss BM, Roschewski M. Multiple myeloma with lacrimal gland amyloidosis and sarcoidosis. Am J Hematol. 2010; 85(7):506-509.

11. Leibovitch I, Selva D, Goldberg RA, Sullivan TJ, Saeed $\mathrm{P}$, Davis G, et al. Periocular and orbital amyloidosis: Clinical characteristics, management, and outcome. Ophthalmology 2006; 113:1657-1664.

12. Mahajan D, Yadava U, Khurana N, Goyal JL. Primary localised nodular amyloidosis of the eyelid and conjunctiva: A case report. Pathology. 2006;38:189-190.

13. Knowles DM, 2nd, Jakobiec FA, Rosen M, Howard G. Amyloidosis of the orbit and adnexae. Surv Ophthalmol. 1975;19:367-384.

14. Cheng JY, Fong KS, Cheah ES, Choo CT. Lacrimal gland amyloidosis. Ophthal Plast Reconstr Surg 2006;22:306-308.

15. Radnot M, Lapis K, Feher J. Amyloid tumor in the lachrymal gland. Ann Ophthalmol. 1971;3:727-735.

16. Massry GG, Harrison W, Hornblass A. Clinical and computed tomographic characteristics of amyloid tumor of the lacrimal gland. Ophthalmology 1996;103:1233-6.

17. Conlon MR, Chapman WB, Burt WL, Larocque BJ, Hearn SA. Primary localized amyloidosis of the lacrimal glands. Ophthalmology 1991;98:1556-1559.

18. Aryasit O, Preechawai P, Kayasut K. Clinical presentation, treatment, and prognosis of periocular and orbital amyloidosis in a university-based referral center. Clinical Ophthalmology 2013:7;801-805.

19. Al Hussain H, Edward DP. Anterior Orbit and Adnexal Amyloidosis. Middle East Afr J Ophthalmol 2013 JulSep;20(3):193-197.

20. Al-Nuaimi D, Bhatt PR, Steeples L, Irion L, Bonshek R, Leatherbarrow B. Amyloidosis of the Orbit and Adnexae. Orbit 31:5, 287-298.

21. Demirci H, Shields CL, Eagle RC, Shields JA. Conjunctival Amyloidosis: Report of Six Cases and Review of the Literature. Surv Ophthalmol 2006;51(4):419-433.

22. Shields JA, Eagle RC, Shields CL, Green M, Singh AD.Systemic amyloidosis presenting as a mass of the conjunctival semilunar fold. Am J Ophthalmol 2000;130(4):523-525.

23. Rodrigues G, Sanghvi V, Lala M. Conjunctival amyloidosis of both eyelids. Ind J Ophthalmol 2001;49(2):116-117.

24. Purcell JJ Jr, Birkenkamp R, Tsai CC, Riner RN. Conjunctival involvement in primary systemic nonfamilial amyloidosis. Am J Ophthalmol1983;95(6):845-847.

25. Marsh WM, Streeten BW, Hoepner JA, Zhang W, Davey FR. Localized conjunctival amyloidosis associated with extranodal lymphoma. Ophthalmology 1987;94(1):61-64.

26. Murdoch IE, Sullivan TJ, Moseley I, Hawkins PN, Pepys MB,Tan SY, et al. Primary localised amyloidosis of the orbit. Br J Ophthalmol 1996;80(12):1083-1086. 
27. Hill VE, Brownstein S, Jordan DR. Ptosis secondary to amyloidosis of the tarsal conjunctiva and tarsus. Am J Ophthalmol 1997;123(6):852-854.

28. Hubbard A, Brown A, Bonshek R, Leatherbarrow B. Surgical management of primary localized conjunctival amyloidosis causing ptosis. Br J Ophthalmol 1995;79(7):707.
29. Dinakaran S, Singh AD, Rennie IG. Orbital amyloidosis presenting as ptosis. Eye 2004;19(1):110-112.

30. Nehen JH. Primary localized orbital amyloidosis. Acta Ophthalmol 1979;57:287-95.

31. Patrinely JR, Koch DD. Surgical management of advanced ocular adnexal amyloidosis. Arch Ophthalmol 1992;110(6):882-885. 